
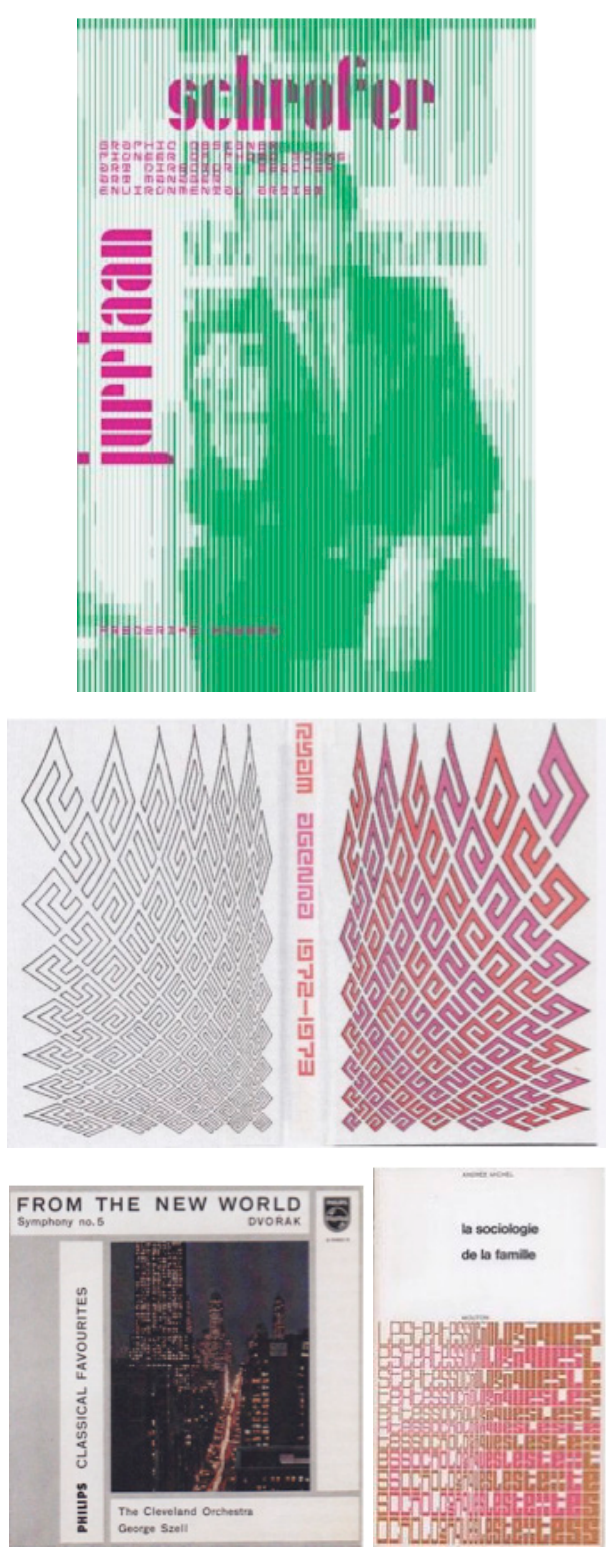

\section{Frederike Huygen}

Juriaan Schrofer (1926-1990): grafisch ontwerper, fotoboekenpionier, art director, docent, kunstbestuurder en omgevingskunstenaar

Amsterdam (Valiz) 20I3, 422 pp., ruim geill., € 39,90 (proefschrift UvA), ISBN 9789078088 69 I

(Engelse uitgave ISBN $9789078088707, € 4 \mathrm{I}, 99)$

Al bladerend in het proefschrift waarop Frederike Huygen op 4 oktober 2013 promoveerde, viel mijn oog op de Rijam-agenda uit het schooljaar I972I973. Ik herkende de omslag direct. Dat gold ook voor de Philips platenhoezen, het bedrijfslogo van Hoogovens, de fotografische beeldverhalen.
De vele boekomslagen van de wetenschappelijke uitgeverij Mouton (p. 30I-325) gewijd aan antropologie, semiologie, stad en taal, herinnerde ik me uit mijn studietijd. Grafische ontwerpen die blijkbaar in mijn geheugen waren gegrift, maar zonder idee van ontwerper en zonder enige notie van de experimenteerzucht, de bezetenheid en de ambachtelijkheid die er aan ten grondslag hadden gelegen. Wat voor mij in de jaren '6o en '70 een vanzelfsprekend kader was geweest, bleek deel uit te maken van een Nederlandse beeldcultuur van formaat, waarbij ik nooit had stilgestaan.

Met deze monografie over Jurriaan Schrofer (1926-1990) heeft Huygen dit buitengewoon interessante dossier van het Nederlands visueel erfgoed in zijn volle breedte voor het voetlicht gebracht. De enorme hoeveelheid informatie, opgediept uit archieven, correspondentie, publicaties, maar ook opgetekend uit de vele gesprekken die zij heeft gevoerd - ik tel er 47 - is overweldigend. Dat gecombineerd met het feit dat het strak vormgegeven proefschrift voor de helft bestaat uit volle pagina's oogstrelend en prikkelend beeldmateriaal - advertenties, affiches, beeldverhalen, huisstijlen, postzegels, bewegwijzering, ruimtelijke werken, belettering in allerlei soorten en maten - maakt dat er een werkstuk ligt dat getuigt van een bewonderenswaardige volharding om al het historisch feitenmateriaal nauwgezet en secuur in kaart te brengen.

Het omvangrijke project wordt door de auteur zelf aangeduid als het reconstrueren van Schrofers werk en werkzaamheden in diverse contexten (p. Io). De hoofdstukken getuigen daarvan: de focus is telkens gericht op een thematisch aspect uit Schrofers veelzijdige werk, waarbij zijn bezigheden chronologisch gevolgd worden en geplaatst in het bijbehorend maatschappelijke (en persoonlijke) kader. Al lezend (en kijkend) doorloop je als lezer zo verschillende malen het creatieve leven van Jurriaan Schrofer: hoofdstuk I 
(leertijd Dick Elffers, Drukkerij Meijer), hoofdstuk 2 (PR-adviseur bedrijven, pionier huisstijlen), hoofdstuk 3 (regisseur fotoboeken), hoofdstuk 4 (visuele en verbale retorica), hoofdstuk 5 (art director, reclame-strateeg), hoofdstuk 6 (beleid, bestuur), hoofdstuk 7 (docent, academiedirecteur) en hoofdstuk 8 (experimenten met letters en tekens). De continue stapeling en verschuiving die Schrofers leven heeft gekenmerkt onderga je als lezer in kort bestek, is intens maar ook verwarrend. Het schema aan het eind (p. 4023) is een welkome accolade van een creatief leven dat bewondering afdwingt, maar dat in zijn kunstzinnige complexiteit en relationele veelvoudigheid nauwelijks is te bevatten.

Schrofers oeuvre kan vanuit vele invalshoeken worden benaderd en dat wordt bevestigd door de domeinen die promotoren en leescommissie vertegenwoordigen (algemene cultuurwetenschappen, boekgeschiedenis, design cultures, moderne kunstgeschiedenis, sociologie van de kunst, typografie, vroegmoderne kunsten). De auteur wijst erop dat het in de Nederlandse designgeschiedenis nog ontbreekt aan een adequate, systematische geschiedschrijving (p. II). Dat vraagt om het formuleren van een onderzoeksobject, een afgebakende vraagstelling, een heldere methode, een consistent begrippenapparaat en een reflectie op het gebruik van heterogene bronnen. In die zin is de keuze voor de kunstsociologie expliciet (p. 9), al blijft het als ordescheppend denkkader in het boek te impliciet, getuige ook de diversiteit in begrippen (Pierre Bourdieu: veld, habitus; Howard Becker: netwerk, art world; Bram Kempers: polemisch verbond). De vraag is voorts hoe deze invalshoek zich verhoudt tot de andere disciplines die worden aangehaald (p. Io): sociaaleconomische ontwerpgeschiedenis, kunstgeschiedenis, fotografiegeschiedenis, ontwerpgeschiedenis, communicatietheorie en visuele perceptie. Elk van die disciplines streeft per slot van rekening een eigen waarheidsvinding na door eigen vragen te stellen aan de bronnen.
Gegeven de keuze voor de kunstsociologie ligt het nauwelijks voor de hand om het kunstbegrip waarop deze discipline berust zelf eerst te onderzoeken. Maar is een kunstsociologie niet pas mogelijk als duidelijk is wat er onder kunst wordt verstaan, wetend dat het begrip een eigen genealogie kent in de westerse geschiedenis der kunsten? Meer precies, is een kunstsociologie van de grafische vormgeving niet pas mogelijk als het moderne discours over grafische vormgeving is geanalyseerd? Juist Schrofers levenswerk roept bij uitstek die vraag op omdat hij zich vele malen over het vak van de grafische vormgeving heeft uitgelaten: in beelden, in beeldvorming van woorden, in beeldverhalen, maar ook in woorden over beelden en over vormgeving. Termen als autonome, vrije kunst tegenover gebonden, communicatieve kunst vallen regelmatig, zoals ook hoog versus laag, systeemontwerpen tegenover experiment, ambachtelijk werk contra intellectualiteit, avant-gardisme in onderscheid tot traditie, regie nemen dan wel democratisch besturen, het zijn even zovele contrasten die de revue passeren. Schrofers esthetische arbeid biedt echter handreikingen om te ontsnappen aan deze negentiende-eeuwse hiërarchische denkwijze. Zijn oeuvre bewijst dat kwaliteit en vormvernieuwing berusten op nauwgezette, ambachtelijke kennis, onvermoeide drang regels toe te eigenen opdat creativiteit en experiment zich kunnen aandienen.

Tegelijk wijst alles erop dat Schrofer zich wat betreft zijn denken niet in één afgebakend discours beweegt. De ambivalentie en tegenstrijdigheid die soms zijn gedachtevorming tekent vindt zijn oorzaak in de verschillende rollen die hij vertolkt, gegeven de verschillende velden waarin hij zich beweegt en communiceert. De woorden die hij gebruikt krijgen in verschillende (artistieke, educatieve, bestuurlijke, politieke) contexten een andere connotatie, met alle gevolgen van dien voor de toenmalige gedachtewisseling, maar ook voor de interpretatie daarvan anno nu. In het verlengde daarvan is het de vraag in hoeverre 
het discours waarin Schrofer denkt opgevat moet worden als beoordelingskader voor zijn vormgevingsproductie. Schrofers kritiek op de Zwitserse typografie en op het werk van Wim Crouwel komt op verschillende plaatsen in het proefschrift terug (p. 49, 169, I85, 193, 195, 226). Dit terwijl al vanaf het begin (p. II) duidelijk wordt dat Schrofer in zijn werk eenzelfde systematiek nastreeft. Wie het beeldmateriaal van beide partijen vergelijkt, zal naast verschillen de fundamentele vormovereenkomsten opmerken tussen beide ontwerpopvattingen. Het is dus minder zwart-wit dan in het denken van betrok- kenen wordt voorgesteld. Hoe ontwerpers denken over wat ze doen is niet bepalend voor wat ze ontwerpen. Woorden en beelden kennen een andere ontwikkelingsgeschiedenis. Los van de waardevolle uitstalling van Schrofers bijdrage aan de Nederlandse beeldcultuur heeft dit proefschrift me er eens te meer van overtuigd dat een systematisch inzicht in het vocabulaire van het grootste belang is voor het denken over de visuele cultuur.

Heidi de Mare 